\title{
Molecular characterization and crystallization behavior of peroxide-induced slightly crosslinked poly(L-lactide) during extrusion
}

\begin{abstract}
Masumi Takamura $^{1,2}$, Tomoyuki Nakamura ${ }^{1}$, Seigou Kawaguchi ${ }^{2}$, Tatsuhiro Takahashi ${ }^{2}$ and Kiyohito Koyama ${ }^{2}$
Reactive extrusion of poly(L-lactide) (PLLA) was carried out in the presence of a small amount of various peroxides with relatively slow decomposition rates. The resulting crosslinked, four-armed randomly branched PLLA ( $\chi$-PLLA) was characterized by size exclusion chromatography equipped with multiangle laser light scattering (SEC-MALS), and the results were interpreted according to the type of peroxide used. A new component with a higher molecular weight than the original PLLA was observed in the SEC-MALS chromatograms of the $\chi$-PLLA. The weight-averaged molecular weight $\left(M_{\mathrm{w}}\right)$ of the $\chi$-PLLA was found to increase with increasing effective radical number per PLLA precursor $(n)$, where $n$ is the overall hydrogen abstraction ability of peroxide times the mole ratio of radical to PLLA precursor molecule. This implies that the hydrogen abstraction ability is a good index for the crosslinking efficiency of PLLA. The extent of branching of $\chi$-PLLA was estimated by the shrinking factor, $\mathrm{g}=\left\langle\boldsymbol{R}_{\mathrm{g}}{ }^{2}\right\rangle_{\mathrm{b}} /\left\langle\boldsymbol{R}_{\mathrm{g}}{ }^{2}\right\rangle_{\mathrm{l}}$, and rationalized with $n$, where $\left\langle\boldsymbol{R}_{\mathrm{g}}{ }^{2}\right\rangle_{\mathrm{b}}$ and $\left\langle\boldsymbol{R}_{\mathrm{g}}{ }^{2}\right\rangle_{\mathrm{I}}$ are the mean square radii of gyration of branched and linear polymers with the same molecular weight, respectively. The nucleation and overall crystallization rate of $\chi$-PLLA in the nonisothermal crystallization from the melt was discussed from the viewpoints of branching and entanglement density.

Polymer Journal (2010) 42, 600-608; doi:10.1038/pj.2010.42; published online 26 May 2010
\end{abstract}

Keywords: crosslinking; hydrogen abstraction ability; long-chain branching structure; nonisothermal crystallization; peroxide; poly(L-lactide); size exclusion chromatography fitted with multiangle laser light scattering

\section{INTRODUCTION}

Poly(L-lactide) (PLLA) is a remarkable material of considerable interest not only as a biodegradable polymer but also as a biologically based polymer, in the sense that it is not derived from petroleum resources. The high mechanical strength and modulus of PLLA enable it to be used as an alternative to commodity plastics such as polystyrene, polyethylene and polypropylene. However, the poor processability of PLLA often limits its applicability to extrusion molding, blow molding and form molding. To overcome this disadvantage, various methods have been used to introduce a branched architecture into the PLLA, including chemical crosslinking, ${ }^{1-4}$ radiation-induced crosslinking ${ }^{1,5-7}$ and peroxide-induced crosslinking. ${ }^{1-4,8-14}$ Among those methods, the peroxide-induced crosslinking process by the addition of a small amount of peroxide to PLLA during extrusion has been widely accepted because of its simplicity.

Peroxide-induced crosslinking of a polymer is believed to follow three key steps: (i) the generation of primary radicals derived from the thermal decomposition of peroxide, (ii) the abstraction of hydrogen from polymer chains by primary radicals to generate polymer radicals and (iii) the bimolecular recombination of polymer radicals to form carbon-carbon crosslinks. (i) Primary radical generation

$\mathrm{RO}-\mathrm{OR} \rightarrow 2 \mathrm{RO} \bullet$ (primary radicals)

(ii) Hydrogen abstraction

$\mathrm{RO} \bullet+\mathrm{P}($ polymer $) \rightarrow \mathrm{P} \bullet($ polymer radical $)+\mathrm{ROH}$

(iii) Bimolecular recombination of polymer radicals

$2 \mathrm{P} \bullet \rightarrow \mathrm{P}-\mathrm{P}$ (crosslinking)

Peroxides are classified into several different types and provide a broad range of reactivities according to their chemical structures. Because the species of peroxide has an important part in both steps (i) and (ii), many researchers have studied the effect of peroxide type on the crosslinking behavior of polymers such as polyethylene ${ }^{15}$ and polypropylene. ${ }^{16,17}$ For example, Chodak and Lazar ${ }^{17}$ demonstrated that the reactivity of primary radicals and their diffusion rate significantly influenced the efficiency of crosslinking in polypropylene.

Watanabe et al. ${ }^{18}$ proposed a new method for the determination of the hydrogen abstraction ability of peroxides using a 2,4-diphenyl4-methyl-1-pentene ( $\alpha$-methyl-styrene dimer, MSD) trapping

${ }^{1}$ Functional Chemicals and Polymers Research Laboratory, NOF Corporation, Aichi, Japan and ${ }^{2}$ Graduate School of Science and Engineering, Yamagata University, Yonezawa, Japan

Correspondence: M Takamura, Functional Chemicals and Polymers Research Laboratory, NOF Corporation, 82, Nishimon, Taketoyo-cho, Chita-gun, Aichi 470-2345, Japan. E-mail: masumi_takamura@nof.co.jp

Received 3 February 2010; revised 28 March 2010; accepted 11 April 2010; published online 26 May 2010 
Addition-fragmentation reactions

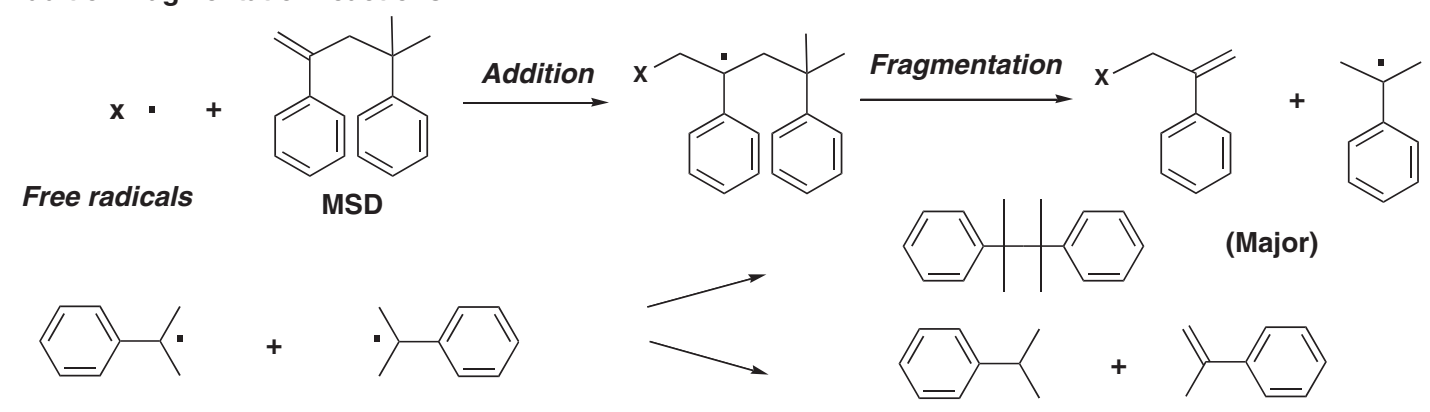

(a)

MSD trapping technique

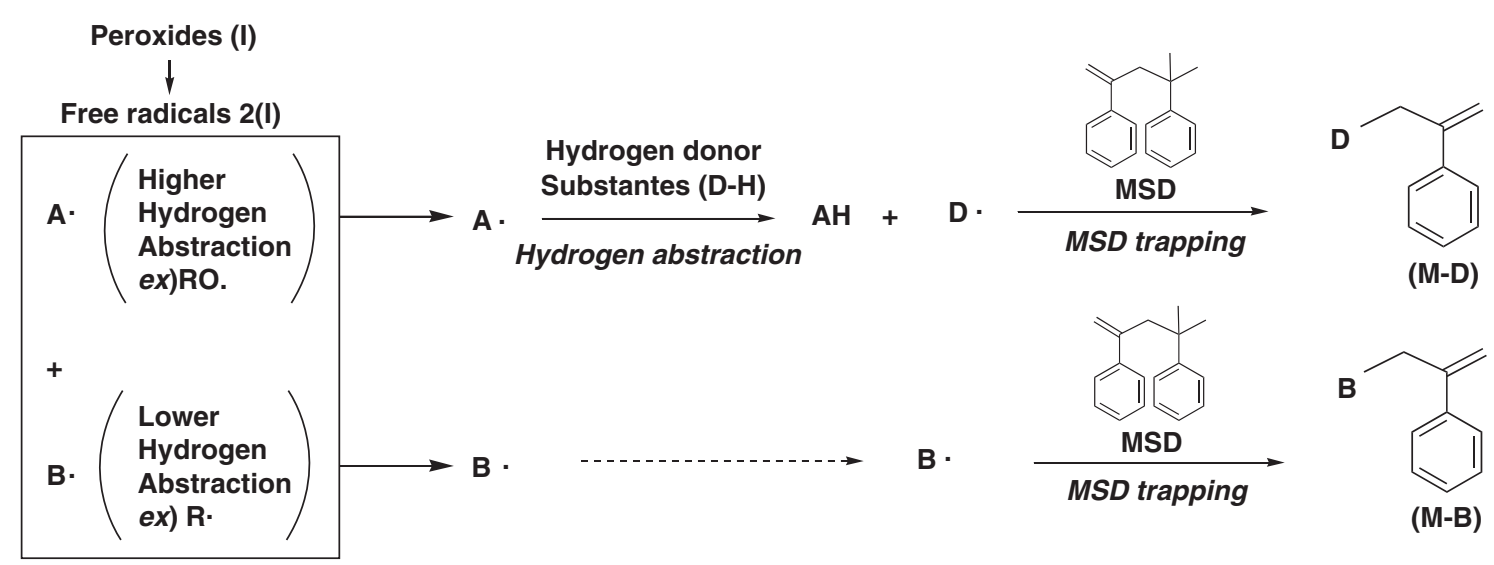

Scheme 1 Addition-fragmentation reactions between free radicals and 2,4-diphenyl-4-methyl-1-pentene ( $\alpha$-methyl-styrene dimer, MSD) and the MSD trapping technique.

technique, ${ }^{19}$ as shown in Scheme 1 . This technique is based on the addition-fragmentation reaction between free radical and MSD (Scheme 1a) ${ }^{20-22}$ and the quick deactivation of cumyl radicals by self-reactions (Scheme 1b-1). When peroxide (I) is decomposed in a mixture of hydrogen donor substrate (D-H) and MSD, some part of peroxide-derived radical $(\mathrm{B} \bullet$ ) is directly trapped by MSD to form an MSD derivative $(\mathrm{M}-\mathrm{B})$. On the other hand, radical $(\mathrm{A} \bullet)$ abstracts a hydrogen from the substrate $(\mathrm{D}-\mathrm{H})$ to give rise to trapping products (M-D). Thus, the yield of trapping products (M-D) against radicals (2I) derived from the initial peroxide (I) is a measure of the hydrogen abstraction ability of the peroxide. Although this technique is highly useful for estimating the overall hydrogen abstraction ability of various peroxide-generating free radicals, few reports describe the connection between the overall hydrogen abstraction ability and the structural characterization of the resulting crosslinked polymers.

In a previous paper, ${ }^{23}$ we reported the details of the relationship between the overall hydrogen abstraction ability of peroxide and peroxide-induced crosslinking of PLLA during reactive extrusion. In the case of slowly decomposed peroxides with lifetimes relatively near the extrusion time, the weight-averaged molecular weight $\left(M_{\mathrm{w}}\right)$ of the peroxide-induced slightly crosslinked PLLA ( $\chi$-PLLA) increased with the increasing overall hydrogen abstraction ability of peroxide. This result was reasonable, given the assumption that the crosslinking reaction occurs after the peroxide disperses and decomposes homogeneously in the molten PLLA. $\chi$-PLLA was also supposed to consist of relatively uniformly branched PLLA with a negligible amount of gel in this crosslinking reaction. However, these speculations were not confirmed because the branched architecture of $\chi$-PLLA was not well characterized. As for the branched PLLA crosslinked by peroxides, several researchers ${ }^{12,24,25}$ have already reported that the crystallization kinetics of the branched PLLA are faster than those of the corresponding linear PLLA. However, the branched architecture has not been characterized in detail. The faster quiescent nucleation and overall crystallization rate of PLLA from the melt state is extremely important for industrial application of PLLA. Therefore, it is essential to clarify the relationship between the branching structure and crystallization behavior of the $\chi$-PLLA.

The aim of this paper is (1) to characterize the long-chain branching (LCB) of $\chi$-PLLA using size exclusion chromatography with the multiangle laser light scattering (SEC-MALS) technique, (2) to obtain a measure characterizing the peroxide-induced crosslinking process and (3) to clarify the influence of the branched architecture of $\chi$-PLLA on crystallization behavior and rheological properties.

\section{EXPERIMENTAL PROCEDURE}

\section{Materials}

Commercial grade PLLA (LACEA H100, 1.5\% D-configuration, 0.14\% residual lactide) was provided by Mitsui Chemicals Inc. (Tokyo, Japan). The absolute number-averaged molecular weight $\left(M_{\mathrm{n}}\right)$ and weight-averaged molecular weight $\left(M_{\mathrm{w}}\right)$ measured by SEC-MALS were 55100 and $81500 \mathrm{~g} \mathrm{~mol}^{-1}$, respectively. Note that the absolute $M_{\mathrm{w}}$ value is about $62 \%$ smaller than the value determined by the conventional calibration curve method with $\mathrm{CHCl}_{3}$ as an eluent, $M_{\mathrm{w}}=132000 \mathrm{gmol}^{-1}$.

Three peroxides were selected as shown in Scheme 2: (1) OO-( $t$-butyl) $O$-(2ethylhexyl) peroxycarbonate (TBEC), lifetime at $200^{\circ} \mathrm{C}: 38 \mathrm{~s}$, overall hydrogen abstraction ability at $140{ }^{\circ} \mathrm{C}$ : $49 \%$; (2) $t$-butyl peroxy benzoate (TBPB), lifetime 
<smiles>CCCCC(CC)COC(=O)OOC(C)(C)C</smiles>

TBEC<smiles>CC(C)(C)OOC(=O)c1ccccc1</smiles>

TBPB

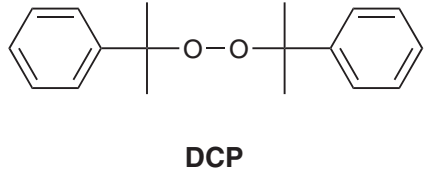

DCP

Scheme 2 Chemical formulas and peroxide abbreviations used in this study.

at $200{ }^{\circ} \mathrm{C}: 60 \mathrm{~s}$, overall hydrogen abstraction ability at $140{ }^{\circ} \mathrm{C}$ : $55 \%$; and (3) dicumyl peroxide (DCP), lifetime at $200^{\circ} \mathrm{C}: 107 \mathrm{~s}$, overall hydrogen abstraction ability at $140{ }^{\circ} \mathrm{C}: 60 \%$. These peroxides have relatively slow decomposition rates when compared with the extrusion time (120s). All peroxides were obtained from the NOF Corporation (Tokyo, Japan) and were used as received. Peroxide lifetime is one of the measures used to quantify the rate of decomposition and is defined here as the time when the ratio of residual peroxide to initial peroxide is 0.0001 . Therefore, lifetime can be calculated using the thermal decomposition parameters of peroxides according to the following equation:

$$
\text { Lifetime }(s)=-\frac{\ln (0.0001)}{k_{\mathrm{d}}}=-\frac{\ln (0.0001)}{A \exp (\Delta E / R T)},
$$

where $k_{\mathrm{d}}\left(\mathrm{s}^{-1}\right)$ is the first-order rate constant of each peroxide, both $A\left(\mathrm{~s}^{-1}\right)$ and $\Delta E\left(\mathrm{~J} \mathrm{~mol}^{-1}\right)$ are the decomposition parameters, ${ }^{26} T$ is the extrusion temperature at the outlet of the extruder $\left(200{ }^{\circ} \mathrm{C}=473 \mathrm{~K}\right)$ and $R$ is the gas constant $\left(8.31 \mathrm{Jmol}^{-1} \mathrm{~K}^{-1}\right)$.

The overall hydrogen abstraction ability of peroxides was determined using the MSD trapping technique described in Scheme 1. From Scheme 1, the overall hydrogen abstraction ability of peroxide can be calculated by the following equation:

$$
\text { Hydrogen abstraction ability }(\%)=\frac{[M-D]}{2[I]} \times 100,
$$

where $[M-D]$ and $[I]$ are the concentrations of $M-D$ and peroxides, respectively.

The molar concentrations of MSD, cyclohexane as a hydrogen donor substrate and initial peroxide were fixed at $1.0,6.9$ and $0.05 \mathrm{M}$, respectively.

Furthermore, to compare the actual characterization of the peroxideinduced slightly crosslinked PLLA ( $\chi$-PLLA) with the corresponding ideal material, the effective radical number per PLLA molecule can be defined as $n$, given by the following equation:

$$
\begin{aligned}
n= & \text { hydrogen abstraction ability } \times \text { feeding mole ratio of } \\
& \text { radical to PLLA precursor molecule }
\end{aligned}
$$

\section{Crosslinking procedure in the extruder}

$\chi$-PLLA was obtained at concentrations of 4.54, 9.07 and $18.15 \mathrm{mmol}$ peroxide/ $1 \mathrm{~kg}$ PLLA. Elementary stoichiometric calculations indicate that $9.07 \mathrm{mmol}$ peroxide $/ 1 \mathrm{~kg}$ PLLA corresponds to one radical per PLLA precursor $\left(55100 \mathrm{~g} \mathrm{~mol}^{-1}\right)$. The $\chi$-PLLA samples crosslinked by peroxide were named as 'Peroxide abbreviation-radical mole content relative to PLLA', such as TBEC-1.

Crosslinking was carried out by reactive extrusion within a corotating twinscrew extruder PCM-30 (Ikegai, Tokyo, Japan; $D=30 \mathrm{~mm}, L / D=30$ ) with a fixed screw speed ( 100 r.p.m.) consisting of three thread starts. The temperature was preset along the extruder from the feeder to the die as 180, 190, 200 and $200{ }^{\circ} \mathrm{C}$ (at die). The extrusion time was around $120 \mathrm{~s}$, measured as the stagnation time of the sample in the extruder from the inlet to the outlet. Previous studies have described the steps of the crosslinking procedure. ${ }^{23}$ To investigate the molecular characterization and crystallization behavior of $\chi$-PLLA, all $\chi$-PLLA samples were obtained by evaporating the gel-filtered $(<0.5 \mu \mathrm{m}) 0.2 \mathrm{wt} \%$ chloroform solution of the extruded $\chi$-PLLA.

\section{Measurements}

SEC-MALS. The SEC-MALS eluent was selected as 1,1,1,3,3,3-hexafluoro-2propanol (HFIP) because of its good solubility and relatively large differential refractive index (RI) for polyesters. The eluent contains $10 \mathrm{~mm}$ sodium 1,1,1trifluoroacetate to yield a reasonable chromatogram. A JASCO SEC system (Pump; PU-2080Plus, Degas; DG-2080-53 and Column Oven; CO-2060Plus: JASCO, Tokyo, Japan) was used with a $2 \times$ Shodex LF-804 column (Showa Denko K.K., Tokyo, Japan). An RI detector (Shodex RI-71, Showa Denko K.K.) was used to determine the concentration $\left(C, \mathrm{~g} \mathrm{ml}^{-1}\right)$. The light scattering instrument, a DAWN-DSP MALS detector (Wyatt Technology, Santa Barbara, CA, USA), operating at $\lambda_{\mathrm{w}}=632.8 \mathrm{~nm}$, was placed between SEC and the RI detector. The Rayleigh ratio $R(90)$ at a scattering angle of $90^{\circ}$ was based on that of pure toluene at a wavelength of $632.8 \mathrm{~nm}$ at $25^{\circ} \mathrm{C}$. The sensitivities of 17 detectors at angles other than $90^{\circ}$ and the dead volume for each detector were corrected for using the scattering intensities of a $0.30 \mathrm{wt} \%$ HFIP solution of poly(methyl methacrylate) standard. The excess RI increment $(\mathrm{d} n / \mathrm{d} c)$ was measured by DRM 1021 (Otsuka Electronics, Tokyo, Japan, operating at $\lambda_{\mathrm{w}}=632.8 \mathrm{~nm}, 25^{\circ} \mathrm{C}$ ) and determined to be $0.155 \mathrm{mlg}^{-1}$ for PLLA in HFIP. This value is high enough to characterize the absolute molecular weight and mean square radius of gyration $\left\langle R_{\mathrm{g}}{ }^{2}\right\rangle$ of a PLLA chain and to compare it with that in chloroform $\left(0.0180 \mathrm{ml} \mathrm{g}^{-1}\right)$ determined in the previous paper. ${ }^{23}$ Polymer sample solutions $\left(0.5-1.0 \mathrm{mg} \mathrm{ml}^{-1}\right.$ in HFIP) were injected into the SEC-MALS columns using a sample loop of $100 \mu \mathrm{l}$ at a flow rate of $0.5 \mathrm{ml} \mathrm{min}^{-1}$. The angular dependence of the scattered light was analyzed in terms of the squareroot plots of $(K C / R(\theta))^{1 / 2}$ with $\sin ^{2}(\theta / 2)$, where $K=4 \pi^{2} n_{\mathrm{o}}{ }^{2}(\mathrm{~d} n / \mathrm{d} c)^{2} /\left(N_{\mathrm{A}} \lambda_{\mathrm{w}}{ }^{4}\right), n_{\mathrm{o}}$ is the RI of the solvent, $N_{A}$ is the Avogadro constant, $\lambda_{\mathrm{w}}$ is the wavelength of the light and $R(\theta)$ is the Rayleigh ratio at the scattering angle $\theta$.

Crystallization behavior. Nonisothermal crystallization was characterized using a differential scanning calorimeter (DSC6200, Seiko Instruments, Tokyo, Japan) under a nitrogen flow $\left(10 \mathrm{ml} \mathrm{min}^{-1}\right)$. The sample was initially heated from $-15^{\circ} \mathrm{C}$ to $220{ }^{\circ} \mathrm{C}$ at $10^{\circ} \mathrm{C} \mathrm{min}^{-1}$ (first heating) and held for $10 \mathrm{~min}$ at $220^{\circ} \mathrm{C}$ to eliminate the thermal history, and subsequently cooled at $-10^{\circ} \mathrm{C} \mathrm{min}^{-1}$ from $220^{\circ} \mathrm{C}$ to $-15^{\circ} \mathrm{C}$ (first cooling) and held for $10 \mathrm{~min}$ at $-15^{\circ} \mathrm{C}$ to observe the crystallization behavior. The degree of crystallinity $\left(X_{\mathrm{c}}\right)$ of the melt at first cooling is calculated from the following equation:

$$
X_{\mathrm{c}}(\%)=\frac{\Delta H_{\mathrm{c}}}{\Delta H_{\mathrm{m}}^{0}} \times 100,
$$

where $\Delta H_{\mathrm{c}}$ is the enthalpy of crystallization at first cooling. $\Delta H_{\mathrm{m}}^{0}$ is the heat of fusion of a perfectly $(100 \%)$ crystalline PLLA $\left(93.6 \mathrm{~J} \mathrm{~g}^{-1}\right) .^{27}$

Rheological measurements. The dynamic viscoelasticity of $\chi$-PLLAs was examined. Shear viscoelastic measurements were determined using ARES (TA Instruments, Tokyo, Japan). Parallel plates with a $25 \mathrm{~mm}$ diameter and a $10 \mathrm{~mm}$ gap height were used for the frequency sweep under a nitrogen atmosphere at $180^{\circ} \mathrm{C}$. The test specimens were cut from a sheet that had been prepared by compression molding at rapid $20^{\circ} \mathrm{C} \mathrm{min}^{-1}$ cooling from the melt $\left(220^{\circ} \mathrm{C}\right.$ in $\left.10 \mathrm{~min}\right)$. The frequency range was $0.1-100 \mathrm{rad} \mathrm{s}^{-1}$, and the maximum strain was fixed at $4 \%$. We confirmed that these conditions were within the linear viscoelastic region.

\section{RESULTS AND DISCUSSION}

\section{Molecular weight distribution and LCB}

Molecular characterization was carried out by SEC-MALS, which gives the absolute $M_{\mathrm{w}}$ and the root-mean squared radius of gyration $\left\langle R_{\mathrm{g}}{ }^{2}\right\rangle^{1 / 2}$ for the polymer fractions eluted from the SEC columns. The absolute $M_{\mathrm{w}}$ and $\left\langle R_{g}{ }^{2}\right\rangle^{1 / 2}$ at each retention volume were determined using Berry's square-root plots. Figure 1 presents molecular weight distribution (MWD) curves for the linear PLLA and 


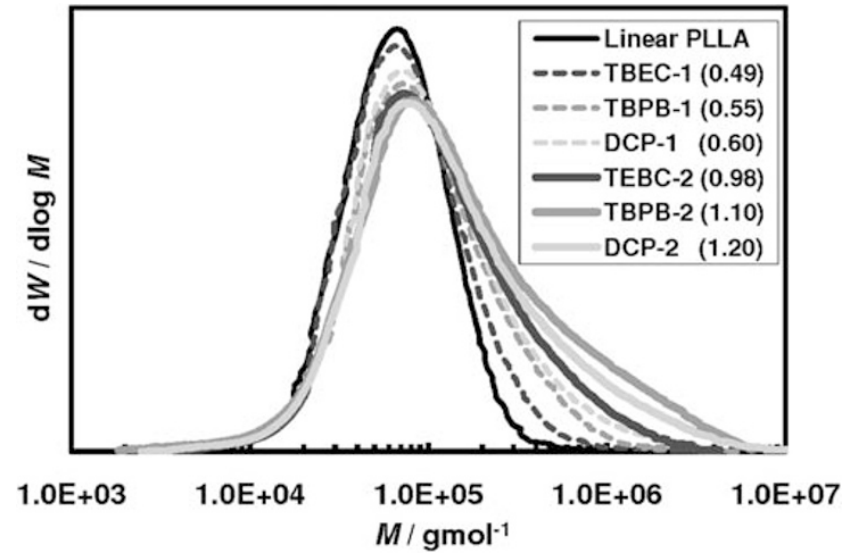

Figure 1 Molecular weight distribution of linear and peroxide-induced crosslinked PLLA obtained by several peroxides. The number after the hyphen indicates the radical mole content relative to PLLA. The number in parentheses represents the number of effective radical moles per PLLA molecule ( $n$; overall hydrogen abstraction ability of peroxide $\times$ molar ratio of radicals to PLLA precursor molecules). A full color version of this figure is available at Polymer Journal online.

$\chi$-PLLAs obtained by the peroxide (OO-(t-butyl) $O$-(2-ethylhexyl) peroxycarbonate, $t$-butyl peroxy benzoate and dicumyl peroxide) reactive excluder. Parent linear PLLA shows a monomodal MWD. In remarkable contrast, the MWD of $\chi$-PLLA clearly shows a tail in the higher molecular weight region that increases with the effective radical number per PLLA molecule $n$ defined in Equation (3).

In the branched polymers, the shrinking factor $g$, which is the ratio of the mean-squared radius of gyration of branched polymer $\left\langle R_{\mathrm{g}}{ }^{2}\right\rangle_{b}$ to that of linear polymer $\left\langle R_{\mathrm{g}}{ }^{2}\right\rangle_{l}$ at the same molecular weight, is introduced as defined by the following equation: ${ }^{28}$

$$
g=\frac{\left\langle R_{\mathrm{g}}^{2}\right\rangle_{b}}{\left\langle R_{\mathrm{g}}^{2}\right\rangle_{l}} .
$$

The radius of gyration depends on the molecular architecture: a $g$ parameter smaller than unity indicates the presence of branching chains. Figure 2 shows the double-logarithmic plot of the radius of gyration $\left\langle R_{\mathrm{g}}{ }^{2}\right\rangle^{1 / 2}$ vs $M_{\mathrm{w}}$ for the linear PLLA and $\chi$-PLLAs. The $\left\langle R_{\mathrm{g}}{ }^{2}\right\rangle^{1 / 2}$ values of $\chi$-PLLAs are remarkably lower than that of linear PLLA, implying a branched architecture at least in the higher $M_{\mathrm{w}}$ region. This plot provides information regarding the conformation of a polymer chain in HFIP solutions. For these samples, the relationship between $\left\langle R_{\mathrm{g}}{ }^{2}\right\rangle^{1 / 2}$ and $M_{\mathrm{w}}$ is well described by the following power law:

$$
\left\langle R_{\mathrm{g}}^{2}\right\rangle^{\frac{1}{2}}=K M_{\mathrm{w}}^{\alpha}
$$

Figure 2 presents the slopes of the $\alpha$ of $\left\langle R_{\mathrm{g}}{ }^{2}\right\rangle^{1 / 2}$ vs $M_{\mathrm{w}}$. The $\alpha$-value for many flexible polymers is 0.50 in a $\theta$-solvent and 0.60 in a good solvent, and a smaller $\alpha$-value than this range suggests the presence of random long-chain branches. ${ }^{29-32}$ Linear PLLA has an $\alpha$-value of 0.59 , implying that a PLLA chain assumes the perturbed random coil conformation in HFIP at $25^{\circ} \mathrm{C} .{ }^{33}$ In remarkable contrast, the $\alpha$-values of $\chi$-PLLAs are between 0.38 and 0.40 , smaller than that of linear PLLA, implying that the degree of branching of $\chi$-PLLA is high enough to result in a decrease in $\left\langle R_{\mathrm{g}}{ }^{2}\right\rangle^{1 / 2}$. Furthermore, similar $\alpha$-values among $\chi$-PLLAs prepared with different peroxides may imply similar branching structures.

The SEC-MALS technique provides information on another important branching characteristic, the number of branches per molecule.

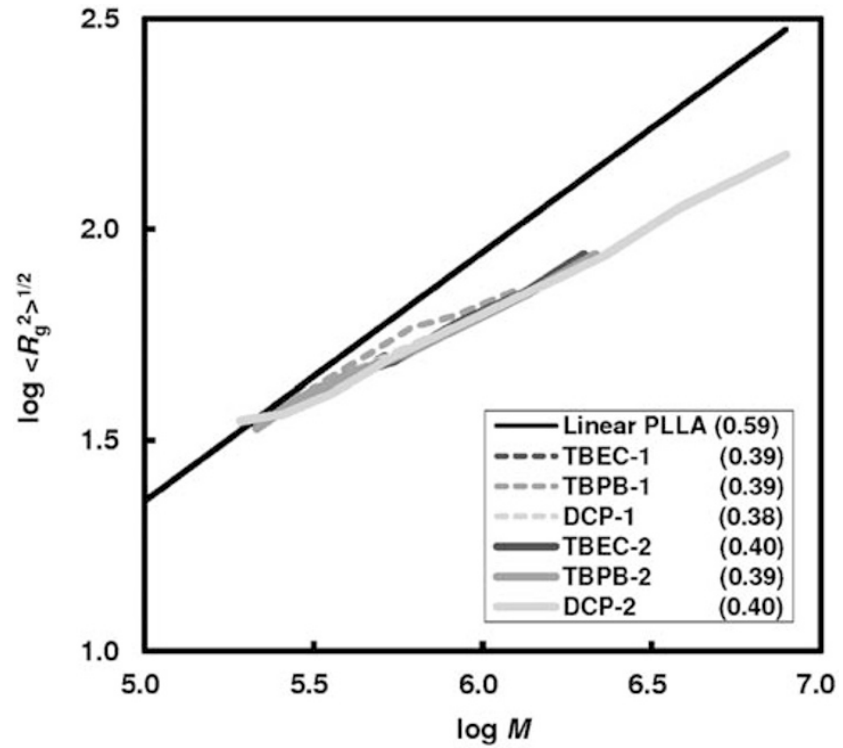

Figure 2 Root-mean squared radius of gyration as a function of the molecular weight of linear and peroxide-induced crosslinked PLLA obtained by several peroxides. The number after the hyphen indicates radical mole content relative to PLLA. The number in parentheses represents the slope of the conformational plots. A full color version of this figure is available at Polymer Journal online.

The relationship between the branching number per molecule and the $g$ parameter depends on the branching functionality and polydispersity of the sample. These results suggest that $\chi$-PLLAs are four-armed randomly branched polymers created by the bimolecular recombination of PLLA radicals with an effective radical number per PLLA precursor molecule $n$ that is less than 1.2. For the four-armed randomly branched polymer that does not contain any cyclic or networked polymers, the shrinking factor $g_{4}$ can be expressed in terms of the number of branches per molecule $m$ of a monodisperse sample at the narrow fraction eluted by the SEC column, as follows: ${ }^{28}$

$$
g_{4}=\left[\left(1+\frac{m}{6}\right)^{\frac{1}{2}}+\frac{4 m}{3 \pi}\right]^{-\frac{1}{2}} .
$$

The LCB frequency $\lambda$ can be calculated, defined as the number of branches per repeat unit of PLLA $\left(R=72 \mathrm{~g} \mathrm{~mol}^{-1}\right)$, as follows:

$$
\lambda=\frac{R m}{M}=72 \frac{m}{M}
$$

Furthermore, to compare the ideal crosslinked density per precursor PLLA calculated as the effective radical number per PLLA precursor molecule $n$ with the corresponding actual one, $\lambda^{\prime}$ can also be calculated as follows:

$$
\lambda^{\prime}=\lambda \times \bar{M} n / R=\bar{M} n \times m / M=55100 \times m / M .
$$

Figures $3 \mathrm{a}$ and $\mathrm{b}$ show the number of branches per molecule $m$ calculated from equation (7) and the LCB frequency $\lambda$ calculated from equation (8), respectively, as a function of molecular weight for $\chi$ PLLA. Figure 3a indicates that the number of branches per molecule $m$ of all $\chi$-PLLAs increases with increasing $M_{\mathrm{w}}$ and that the maximum $m$ of each $\chi$-PLLA increases with an increase in the effective radical number per PLLA precursor molecule $n$.

Figure $3 \mathrm{~b}$ indicates that the LCB frequency $\lambda$ of all $\chi$-PLLAs reaches a constant value when $M_{\mathrm{w}}$ of $\chi$-PLLAs is more than $10^{5.7}$. Each 

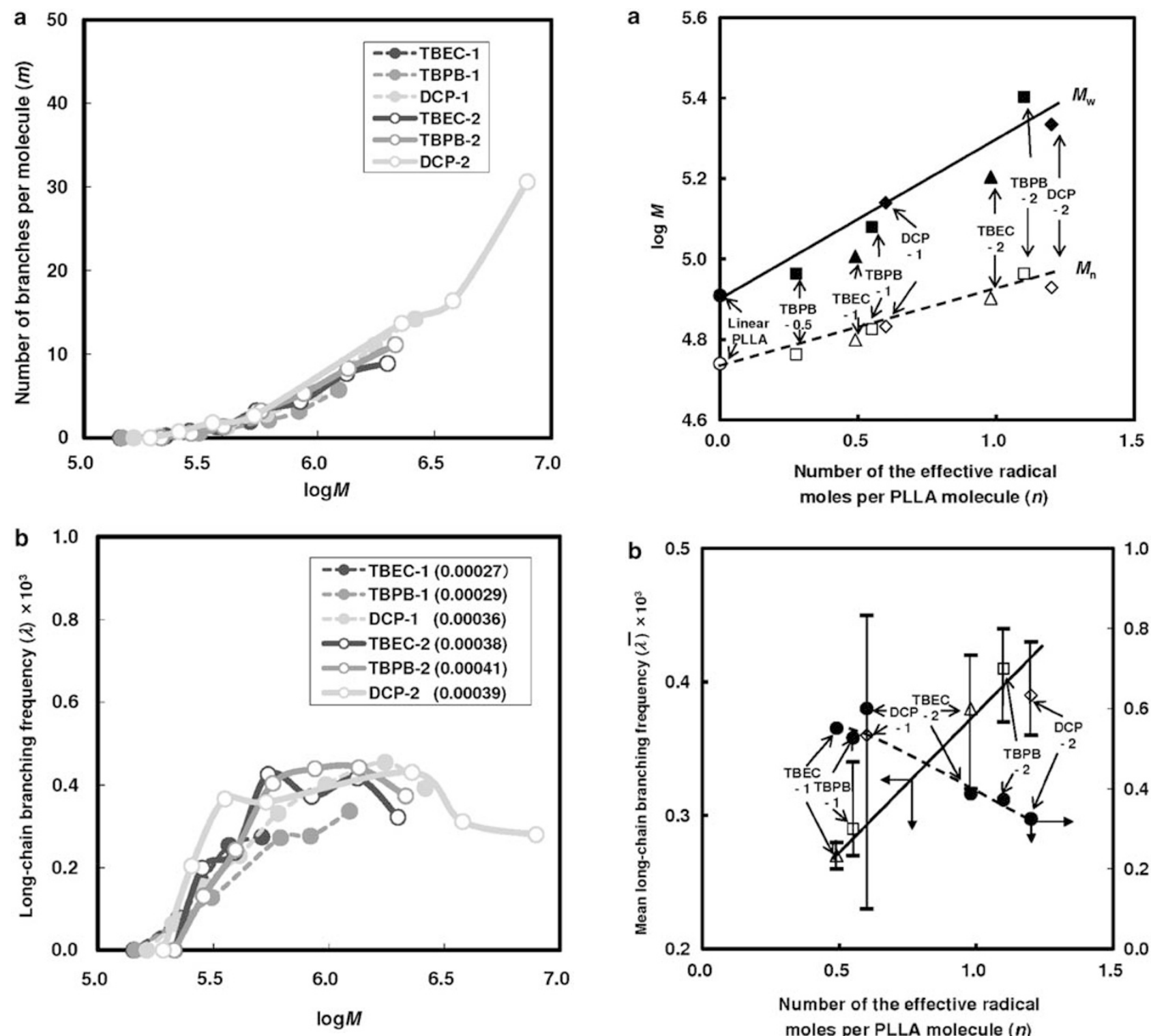

Figure 3 Branching degree of peroxide-induced crosslinked PLLA obtained by several peroxides. The number after the hyphen indicates radical mole content relative to PLLA: (a) the number of branches per molecule $m$, (b) the long-chain branching frequency $\lambda$. The number in the parentheses represents the mean long-chain branching frequency $\bar{\lambda}$. A full color version of this figure is available at Polymer Journal online.

fraction of $\chi$-PLLAs less than $10^{5.7}$ in the SEC chromatogram is considered to be a mixture of coeluted linear and branched species because the highest $M_{\mathrm{w}}$ of original precursor PLLA is around $10^{5.7}$, as shown in Figure 1. On the other hand, each fraction more than $10^{5.7}$ is considered to be the branched species only. The constant value of $\lambda$ above $10^{5.7}$ implies that the crosslinking reaction may have homogeneously occurred in the molten PLLA.

Figures $4 \mathrm{a}$ and $\mathrm{b}$ show the size of the $\chi$-PLLA molecule $(\log M)$ and the mean LCB frequency $(\bar{\lambda})$, respectively, in the higher-molecular-weight region above $10^{5.7}$ as a function of the effective radical number per PLLA molecule $n$. Figure 4a shows good proportional relationships between the effective radical number $n$ and $M\left(M_{\mathrm{n}}, M_{\mathrm{w}}\right)$, as well as polydispersity $\left(M_{\mathrm{w}} / M_{\mathrm{n}}\right)$. In addition, Figure $4 \mathrm{~b}$ also shows a good proportional

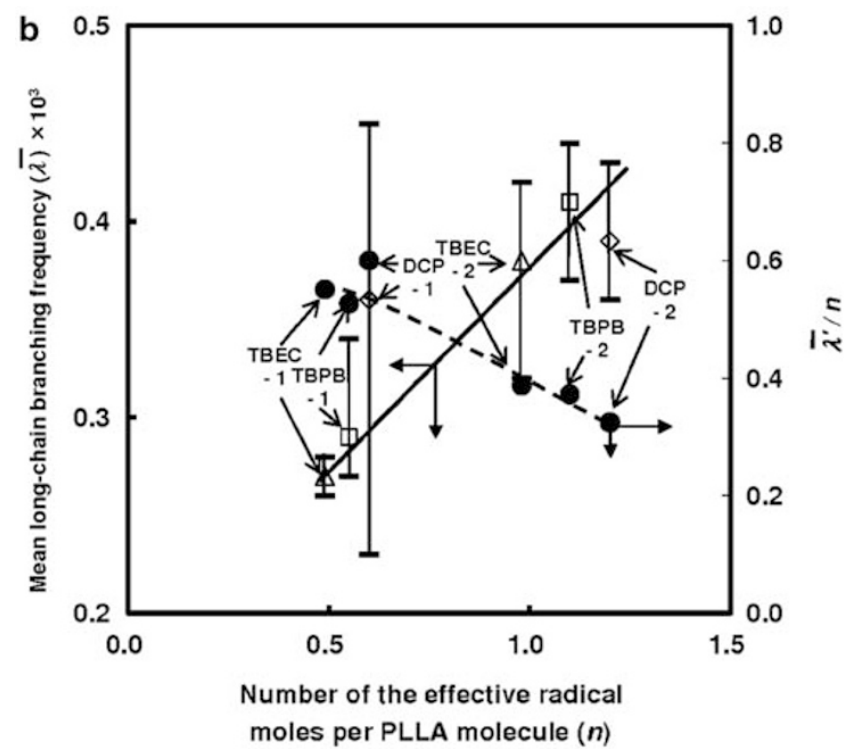

Figure 4 Influence of the number of effective radical moles per PLLA molecule $n$ on the branching structure of peroxide-induced crosslinked PLLA: (a) the size of $\chi$-PLLA molecules $\log M$, (b) the mean long-chain branching frequency $\bar{\lambda}$.

relationship between $n$ and $\bar{\lambda}$. These results suggest that the concentration of branched PLLA with a higher molecular weight compared with linear PLLA increases with increasing $n$ in $\chi$-PLLAs composed of linear and branched PLLA. This result obviously allows for the conclusion that the hydrogen abstraction ability is a good index for the efficiency of PLLA crosslinking, regardless of the type and concentration of the peroxide.

To compare the ideal effective radical number per PLLA precursor molecule $n$ with the corresponding actual value $\lambda^{\prime}, \lambda^{\prime} / n$ is shown in Figure $4 \mathrm{~b}$ as a function of $n$. The $\lambda^{\prime} / n$ reaches a low point $(0.3-0.6)$ and decreases as $n$ increases. The lower value of $\lambda^{\prime} / n$ than unity may imply a lower free radical efficiency $f$ of peroxide in the higher viscosity molten PLLA when compared with that of the MSD trapping system. The decrease in $\lambda^{\prime} / n$ with increasing $n$ is most likely due to the fact that as $n$ becomes higher, the deactivation of peroxide such as radical-induced decomposition occurs in high viscosity molten PLLA. 
Nonisothermal crystallization behavior

Figure 5a shows the differential scanning calorimeter cooling traces of $\chi$-PLLA crosslinked by several peroxides while keeping the radical content fixed at one mol per PLLA precursor molecule. The crystallization parameters shown in Figure $5 \mathrm{~b}$ were determined according to the method of Gupta and Purwar ${ }^{34}$ and are listed in Table 1. The initial slope $S_{\mathrm{i}}$ of the crystallization peak characterizes the initial nucleation rate. That is, the larger the $S_{\mathrm{i}}$ value the higher the nucleation rate. In addition, the difference between the initial crystallization temperature $T_{\mathrm{c}}$ and the peak crystallization temperature $T_{\mathrm{p}}\left(T_{\mathrm{c}}-T_{\mathrm{p}}\right)$ represents the overall crystallization rate, where a lower temperature difference indicates a higher overall crystallization rate.

As shown in Figure 5a, the exothermic melt-crystallization of linear PLLA is hardly found, whereas those of $\chi$-PLLAs are clearly observed. Table 1 shows that $T_{\mathrm{c}}, T_{\mathrm{p}}$ and $S_{\mathrm{i}}$ each show a maximum but $\left(T_{\mathrm{c}}-T_{\mathrm{p}}\right)$ shows a minimum as the $M_{\mathrm{w}}$ value or the mean LCB frequency $\bar{\lambda}$ increases. In Figure 6 , the overall crystallization rate $\left(T_{\mathrm{c}}-T_{\mathrm{p}}\right)$, the degree of crystallinity $X_{\mathrm{c}}$ and the initial nucleation rate $S_{\mathrm{i}}$ are plotted against $\bar{\lambda}$. Figure 6 a shows that $\left(T_{\mathrm{c}}-T_{\mathrm{p}}\right)$ value decreases linearly and the degree of crystallinity $X_{\mathrm{c}}$ increases with increasing $\bar{\lambda}$. That is, the overall crystallization rate and the degree of crystallinity of PLLA are
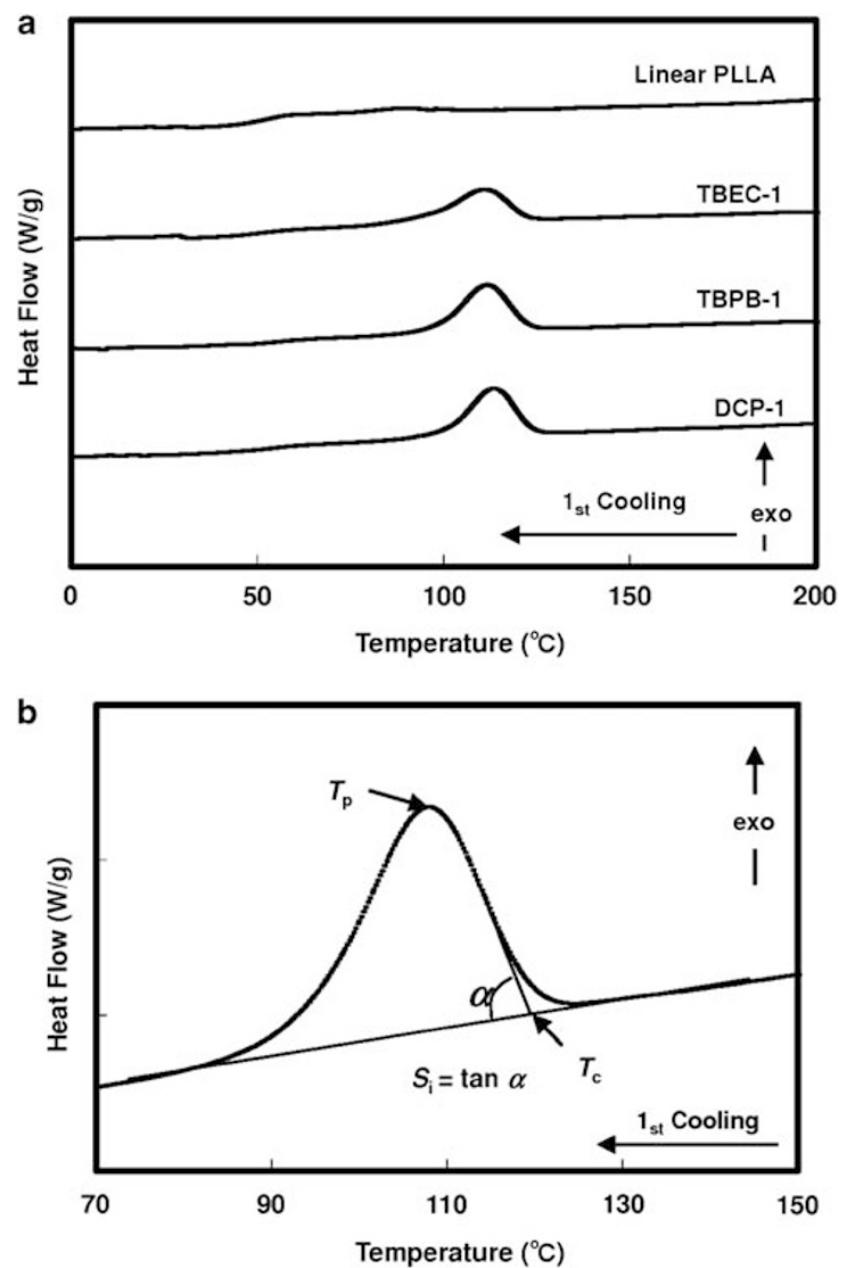

Figure 5 Differential scanning calorimeter (DSC) cooling behavior of linear PLLA and $\chi$-PLLA: (a) DSC cooling traces of $\chi$-PLLA crosslinked by several peroxides while keeping the radical content fixed at one mol per PLLA precursor molecule, (b) DSC curve illustrating nonisothermal crystallization according to the method of Gupta and Purwar. ${ }^{34}$
Table 1 Crystallization parameter of slightly peroxide-induced crosslinked PLLA

\begin{tabular}{|c|c|c|c|c|c|c|c|}
\hline Code & $\begin{array}{c}M_{W}{ }^{\mathrm{a}} \\
\left(10^{4} \mathrm{~g} \mathrm{~mol}^{-1}\right)\end{array}$ & $\begin{array}{c}\lambda^{b} \\
\left(10^{-3}\right)\end{array}$ & $T_{p}\left({ }^{\circ} \mathrm{C}\right)$ & $T_{C}\left({ }^{\circ} \mathrm{C}\right)$ & $T_{C}-T_{p}\left({ }^{\circ} C\right)$ & $S_{i}$ & $X_{c}(\%)$ \\
\hline Liner PLLA & 8.2 & - & - & - & - & - & 1.0 \\
\hline TBEC- $1^{\mathrm{C}}$ & 10.2 & 0.27 & 107.0 & 118.2 & 11.2 & 5.2 & 40.1 \\
\hline TBPB-1C & 12.1 & 0.29 & 111.0 & 121.2 & 10.2 & 7.9 & 43.9 \\
\hline DCP $-1^{\mathrm{C}}$ & 13.5 & 0.36 & 112.2 & 120.0 & 7.8 & 13.9 & 46.7 \\
\hline TBEC-2 ${ }^{d}$ & 16.0 & 0.38 & 119.9 & 126.8 & 6.9 & 15.9 & 49.5 \\
\hline TBPB-2 ${ }^{\mathrm{d}}$ & 25.3 & 0.41 & 123.3 & 128.7 & 5.4 & 31.7 & 51.6 \\
\hline DCP-2 ${ }^{d}$ & 21.6 & 0.39 & 113.4 & 121.0 & 7.6 & 13.2 & 50.7 \\
\hline
\end{tabular}

Abbreviations: DCP, dicumyl peroxide; PLLA, poly(L-lactide); SEC-MALS, size exclusion chromatography equipped with multi-angle laser light scattering; TBEC, $O O$-( $t$-butyl) $O-(2$ ethylhexyl) peroxycarbonate; TBPB, $t$-butyl peroxy benzoate.

aMeasured by SEC-MALS.

Mean long-chain branching frequency measured by SEC-MALS at higher molecular weight region (more than $10^{5.7}$ ).

CRadical content was fixed at $1 \mathrm{~mol}$ per PLLA molecule.

dRadical content was fixed at 2 mol per PLLA molecule.
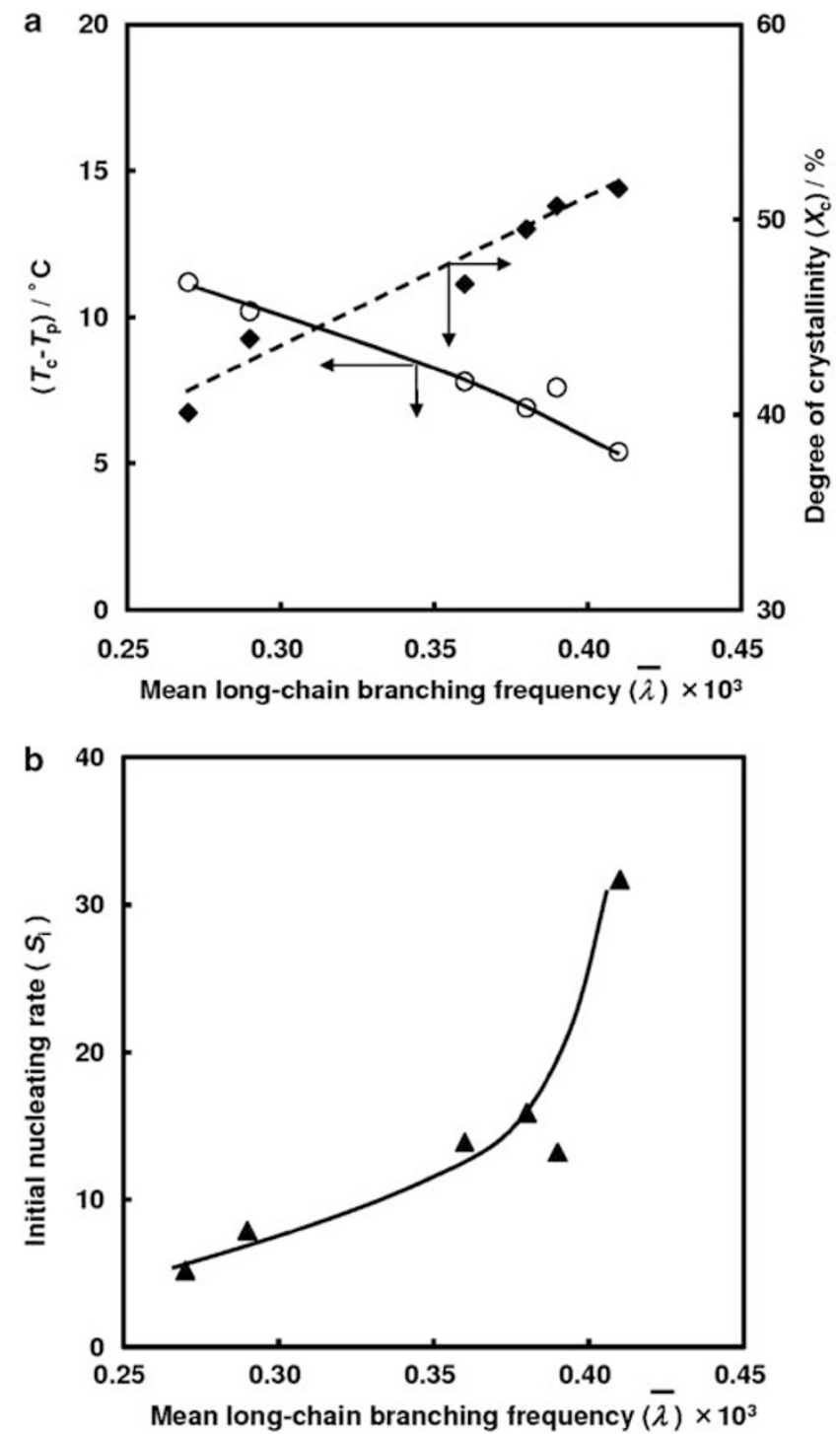

Figure 6 Influence of the mean long-chain branching frequency $\lambda$ on nonisothermal crystallization behavior: (a) the total crystallization rate $\left(T_{\mathrm{c}}-T_{\mathrm{p}}\right)$, the degree of crystallinity $X_{\mathrm{c}},(\mathbf{b})$ the initial nucleation rates $S_{\mathrm{i}}$. 
greatly enhanced by the presence of the branching architecture. Few studies have reported the influence of the LCB frequency of $\chi$-PLLA, although several studies ${ }^{12,24,25}$ have described the fast crystallization behavior of $\chi$-PLLA.

Polymer crystallization from the melt occurs by means of two main mechanisms: nucleation and crystal growth. The crystal growth mechanism of PLLA crystallization has been widely investigated. Wang and Dong ${ }^{35}$ investigated the crystal growth kinetics of fourarm star-shaped well-defined PLLA $\left(M_{\mathrm{n}}=1.3 \times 10^{4}, M_{\mathrm{w}} / M_{\mathrm{n}}=1.05\right)$ synthesized with four-functional primary alcohol. They observed a significant decrease in the spherulitic growth rate for the four-arm star-shaped well-defined PLLA and explained this by the lower molecular mobility and rearrangement ability. However, the nucleation mechanism has not been discussed in the literature.

Crystallization from the melt occurs when the nucleation process is more dominant than the crystal growth process. Two widely accepted nucleation mechanisms are homogeneous nucleation and heterogeneous nucleation. The former occurs through the random fluctuations of macromolecules that result in a favorable alignment of polymer chains. The latter occurs more commonly at the interface of a second phase. As shown in Figure 6b, the initial nucleation rate $S_{\mathrm{i}}$ increases exponentially with the mean LCB frequency $\bar{\lambda}$. In other words, the quantity of branched PLLA in $\chi$-PLLA strongly affects the initial nucleation rate, implying that the branched points may function as heterogeneous nucleation sites. This may correspond to the higher overall crystallization rate and the higher degree of crystallinity with increasing mean LCB frequency $\bar{\lambda}$.

In addition, the nucleation rate is strongly affected by the pretreatment or thermal history of the previous process. In this experiment, all samples were obtained by evaporation drying at $40{ }^{\circ} \mathrm{C}$ of a $0.2 \mathrm{wt} \%$ solution in chloroform and held in the molten state $\left(220^{\circ} \mathrm{C}\right)$ for $10 \mathrm{~min}$ after the thermal history of the first heating $\left(-15\right.$ to $220^{\circ} \mathrm{C}$, $10^{\circ} \mathrm{C} \mathrm{min}{ }^{-1}$ ) before the first cooling. The viscosity of the molten state is low enough for linear PLLA to remove any crystal nuclei from the samples, because Vasanthankumari and Pennings, ${ }^{36}$ Tsuji and Ikada, ${ }^{37}$ and Kalb and Pennings ${ }^{38}$ reported equilibrium melting temperatures $\left(T_{\mathrm{m}}^{\circ}\right)$ for PLLA at 207,205 and $215^{\circ} \mathrm{C}$, respectively. However, for $\chi$-PLLA, including high-molecular-weight highly branched PLLA, the temperature of $220^{\circ} \mathrm{C}$ may not be high enough because of high entanglement with itself or with linear PLLA.

Figure 7 shows the dynamic moduli and dynamic shear viscosity of linear PLLA and $\chi$-PLLA obtained by peroxides $O O$-( $t$-butyl) $O$-(2-ethylhexyl) peroxycarbonate and $t$-butyl peroxy benzoate while keeping the radical content fixed at two moles per PLLA precursor molecule. Figure 7 indicates that $\chi$-PLLA has a long relaxation time and a high dynamic shear viscosity based on the order of the hydrogen abstraction ability.

As for the rheological aspects of quiescent crystallization from the melt, Shroff et al. ${ }^{39}$ demonstrated that there is a direct correlation between the rheological parameter elasticity index $E_{\mathrm{R}}$ of the commercial high-density polyethylene including LCB and the isothermal overall crystallization rates. $E_{\mathrm{R}}$ is normalized to remove the effect of molecular weight and is calculated from the data obtained from shear viscoelastic measurements. A plot of $\log G^{\prime}$ against $\log G^{\prime \prime}$ (Figure 8a) based on the data presented in Figure 7a shows that the data of each polymer fall in a straight line. A measure of MWD and LCB at the high-molecular-weight end is derived by fitting six pairs of lowest-frequency data to a straight line using the following linear regression:

$$
\log G^{\prime}=C_{1} \log G^{\prime \prime}+C_{2},
$$
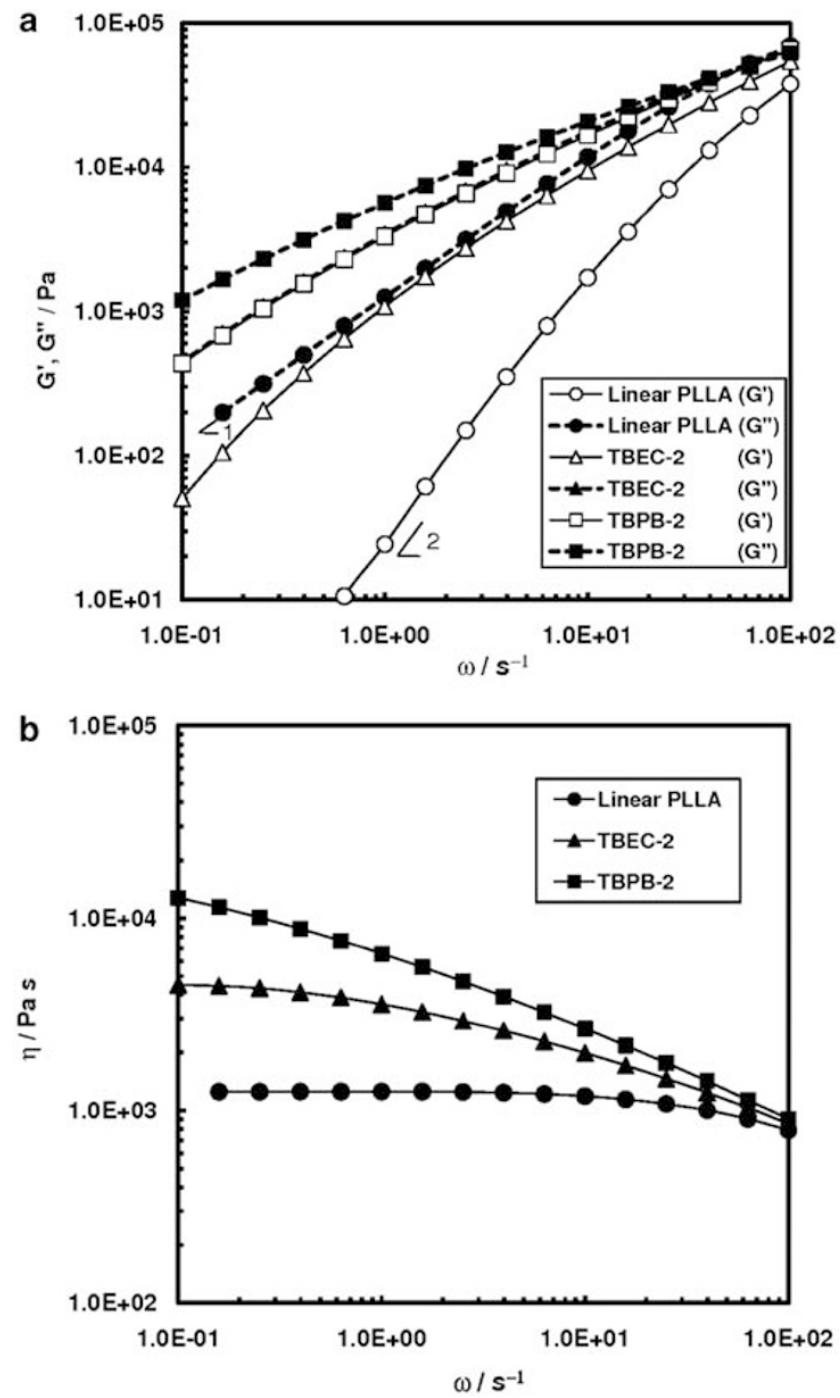

Figure 7 The dynamic viscoelasticity of linear PLLA and $\chi$-PLLAs obtained by peroxides (OO-( $t$-butyl) $O$-(2-ethylhexyl) peroxycarbonate (TBEC) and $t$-butyl peroxy benzoate (TBPB)): (a) dynamic moduli and (b) dynamic shear viscosity. The number after the hyphen indicates the radical mole content relative to PLLA.

where $C_{1}$ and $C_{2}$ are constants. Here, we invoke a term called elasticity index $E_{\mathrm{R}}$, which is defined as

$$
E_{\mathrm{R}}=\left.C_{3} G^{\prime}\right|_{G^{\prime \prime}=500 \mathrm{~Pa}},
$$

where the value of $C_{3}$ is arbitrarily 0.1 or 20 . Figure 8 a shows an example of calculating the elasticity index $E_{\mathrm{R}}$, in which the elasticity index $E_{\mathrm{R}}$ is the cross-point of the line $G^{\prime \prime}=500 \mathrm{~Pa}$ (lower frequency) and each straight line.

Figure $8 \mathrm{~b}$ shows the relationship between the mean LCB frequency $\bar{\lambda}$ and the elasticity index $E_{\mathrm{R}}$. The elasticity index $E_{\mathrm{R}}$ increases exponentially with increasing mean LCB frequency $\bar{\lambda}$. This implies that branch points impart stiffness to molten PLLA and that nucleating agents reduce the free energy of a nucleus $\Delta G$.

Figure 9 shows the time to $T_{\mathrm{p}}$ from $220^{\circ} \mathrm{C}$ against $E_{\mathrm{R}}$. In this figure, the corresponding $T_{\mathrm{p}}$ is also indicated in the right axis. This plot indicates that there is an asymptotic decrease in time to the maximum overall crystallization rates with increasing $E_{\mathrm{R}}$ that corresponds to the 

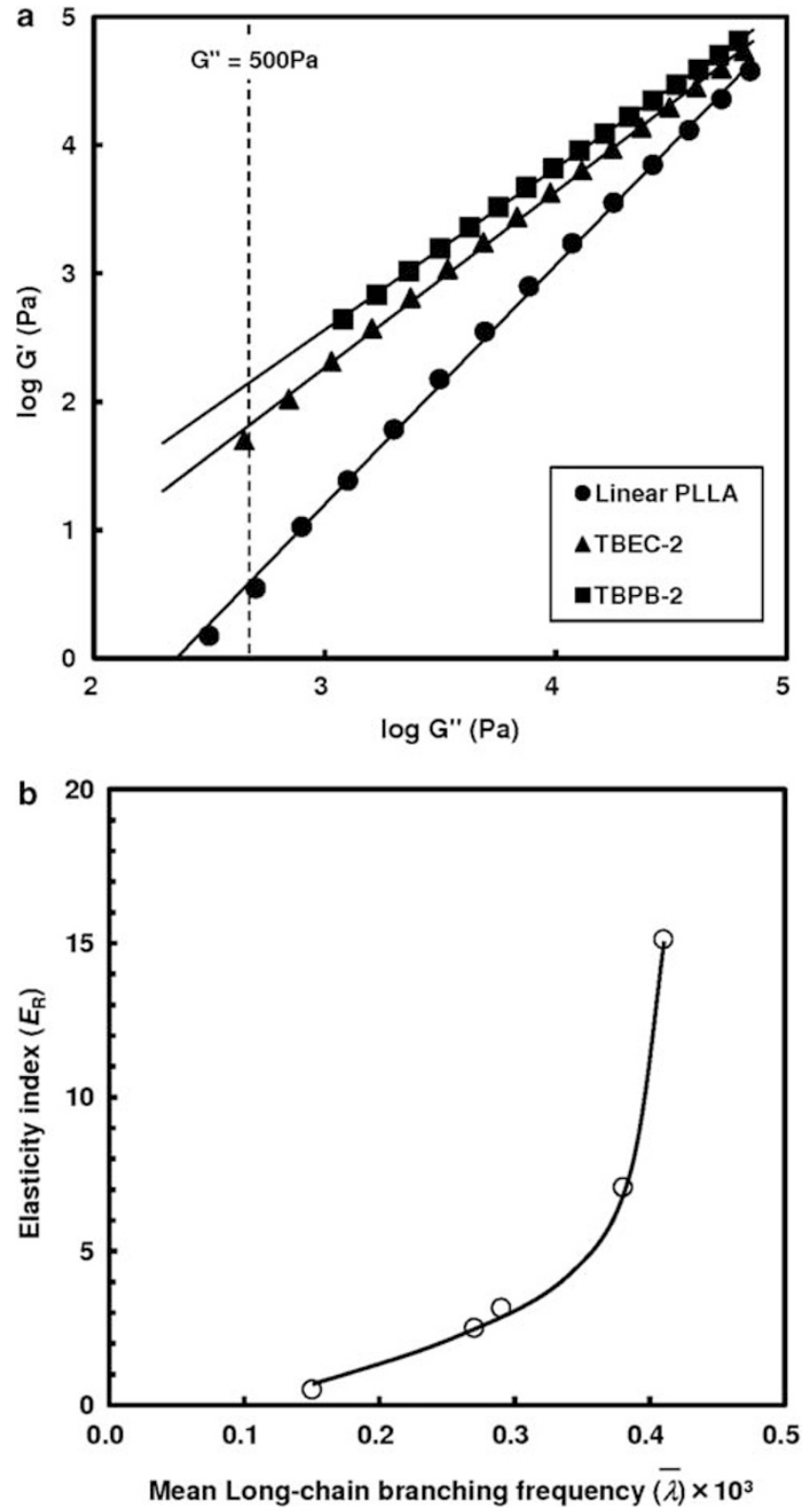

Figure 8 An example calculation of the elasticity index $E_{R}$ : (a) log $G^{\prime}$ against $\log G^{\prime \prime}$ of linear PLLA and $\chi$-PLLAs obtained by peroxides (OO-(t-butyl) $O$-(2ethylhexyl) peroxycarbonate (TBEC) and $t$-butyl peroxy benzoate (TBPB). The number after the hyphen indicates radical mole content relative to PLLA. (b) The relationship between the mean long-chain branching frequency $\lambda$ and the elasticity index $E_{R}$.

concentration of nucleating agents as mentioned above. On the other hand, $E_{\mathrm{R}}$ increases with increasing $T_{\mathrm{p}}$. In rheological measurements, $E_{\mathrm{R}}$ increases as the measuring temperature decreases. Thus, $\chi$-PLLA with a low $E_{\mathrm{R}}$ requires a higher undercooling temperature to form the primary nucleus.

This allows for the conclusion that besides crystallizability or crystallization rates, rheological changes also control the optical and other physical properties of polymers. The rheological and physical properties are both governed by changes in the chemical structure and the state of entanglement of the polymer. Conversely, minute changes in the molecular structure and shear history imposed during processing may dramatically influence the crystallizability of the resin. Future

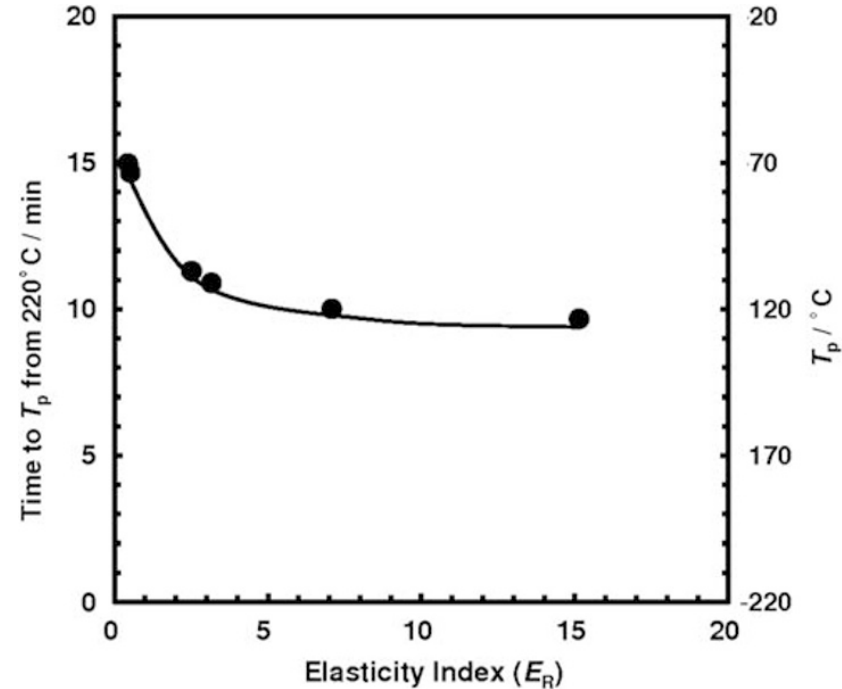

Figure 9 Plot of the time to peak crystallization temperature $T_{\mathrm{p}}$ from $220^{\circ} \mathrm{C}$ against the elasticity index $E_{\mathrm{R}}$.

experiments will more closely investigate the effect of the structure of branched PLLA on the kinetics of isothermal crystallization and on rheological properties.

\section{CONCLUSIONS}

Molecular characterization of $\chi$-PLLA prepared by peroxides with relatively slow decomposition rates was investigated in detail using SEC-MALS. Assuming that $\chi$-PLLAs consist of a tetra-functional randomly branched polymer, the $m$ of all $\chi$-PLLAs increases with increasing molecular weight and the maximum $m$ of each $\chi$-PLLA increases with an increase in the effective radical number per PLLA molecule $n$. On the other hand, there is an obvious relationship between the mean LCB frequency $\bar{\lambda}$ and $n$. These results suggest that the concentration of branched PLLA with a higher molecular weight than that of linear PLLA increases with increasing $n$ in $\chi$-PLLAs composed of linear and branched PLLA. Furthermore, these results obviously show that hydrogen abstraction ability is a good index for determining the efficiency of PLLA crosslinking, regardless of the type of peroxide. These results also show that the size of $\chi$-PLLA molecule increases while keeping a fixed crosslinked density as $n$ becomes higher. On the other hand, as for the crystallization behavior of $\chi$-PLLA, both the mean LCB frequency $\bar{\lambda}$ and the elasticity index $E_{\mathrm{R}}$ affect the nucleating rate. These results indicate that branch points and entanglement density have remarkable effects on the nucleation rate, the overall crystallization rate and the degree of overall crystallinity.

\section{ACKNOWLEDGEMENTS}

We express our grateful appreciation to associate professor Masataka Sugimoto, Yamagata University, for valuable suggestions and discussions. We also thank Mr Daiki Izuta and Mr Hideyuki Uematsu for SEC-MALS and dynamic viscoelasticity measurements, respectively.

1 Nijenhuis, A. J., Grijpma, D. W. \& Pennings, A. J. Crosslinked poly(L-lactide) and poly(عcaprolactone). Polymer 37, 2783-2791 (1996).

2 Hartmann, M. H. in Biopolymers from Renewable Resources (ed by Kaplan D.L.) Ch. 15, 367-411 (Springer-Verlag, Berlin, 1998). 
3 Gruber, P. R., Hartmann, M. H., Kolstad, J. J., Witzke, D. R. \& Brosch, A. L. (Cargil Co.): USA, PCT94/08 508 (1996).

4 Ryan, C. M., Hartmann, M. H. \& Nangeroni, J. F. Branching of poly(lactic acid) to increase melt strength for extrusion coating. in Polymers, Laminations, and Coatings Conference TAPPI Proceedings, 139-144 (1997).

5 Babanalbandi, A., Hill, D. J. T. \& Whittaler, A. K. Volatile products and new polymer structures formed on ${ }^{60} \mathrm{Co} \gamma$-radiolysis of poly(lactic acid) and poly(glycolic acid). Polym. Degrad. Stab. 58, 203-214 (1997).

6 Burdick, J. A., Frankel, D., Dernall, S. \& Anseth, K. S. An initial investigation of photocurable three-dimensional lactic acid based scaffolds in a critical-sized cranial defect. Biomaterials 24, 1613-1620 (2003).

7 Mimoto, H., Kaneda, A., Quynh, T. M., Nagasawa, N. \& Yoshii, F. Improvement of heat stability of poly(I-lactic acid) by radiation-induced crosslinking. Polymer 46, 4695-4703 (2005).

8 Sodergard, A. \& Nasman, J. H. Stabilization of poly(L-lactide) in the melt. Polym. Degrad. Stab. 46, 25-30 (1994).

9 Sodergard, A., Niemi, M., Selin, J. F. \& Nasman, J. H. Changes in peroxide meltmodified poly(L-lactide). Ind. Eng. Chem. Res. 34, 1203-1207 (1995).

10 Sodergard, A. \& Nasman, J. H. Melt stability study of various types of poly(L-lactide). Ind. Eng. Chem. Res. 35, 732-735 (1996).

11 Sodergard, A., Niemi, M., Selin, J. F. \& Nasman, J. H. Hydrolytic degradation of peroxide modified poly(L-lactide). Polym. Degrad. Stab. 51, 351-359 (1996).

12 Dorgan, J. R., Lehermier, H. \& Mang, M. Thermal and rheological properties of commercial-grade poly(lactic acid)s. J. Polym. Envir. 8, 1-9 (2000)

13 Carlson, D., Dubois, P., Nie, L. \& Narayan, R. Free radical branching of polylactide by reactive extrusion. Polym. Eng. Sci. 38, 311-321 (1998).

14 Takagi, J., Nemoto, T., Miyazaki, M., Nishioka, A., Takimoto, J. \& Koyama, K. The improvement of plastic processability of poly (L-lactic acid) modified by dicumyl peroxide. Seikei-Kakou 14, 598-603 (2002).

15 Zhou, W. \& Zhu, S. ESR study of peroxide-induced cross-linking of high density polyethylene. Macromolecules 31, 4335-4341 (1998).

16 Borsig, E., Fiedlerova, A. \& Lazer, M. Efficiency of chemical cross-linking of polypropylene. J. Macromol Sci. Chem. A16, 513-528 (1981)

17 Chodak, I. \& Laser, M. Effect of the type of radical initiator on crosslinking of polypropylene. Angew. Macromol. Chem. 106, 153-160 (1982).

18 Watanabe, Y., Ishigaki, H., Okada, H. \& Suyama, S. New method for determination of hydrogen abstraction ability of organic peroxides. Pol. J. 29, 940-943 (1997).

19 Watanabe, Y., Ishigaki, H., Okada, H. \& Suyama, S. New method in free radical chemistry using 2,4-diphenyl-4-methyl-1-pentene as radical trapping agent. Pol. J. 29, 366-369 (1997).

20 Watanabe, Y., Ishigaki, H., Okada, H. \& Suyama, S. Addition-fragmentation chain transfer in free radical styrene polymerization in the presence of 2,4-diphenyl-4methyl-1-pentene. Chem. Lett. 5, 1089-1092 (1993).

21 Suyama, S., Ishigaki, H., Watanabe, Y. \& Nakamura, T. Crosslinking of polyethylene by dicumyl peroxide in the presence of 2,4-diphenyl-4-methyl-1-pentene. Pol. J. 27, 371-375 (1995).
22 Suyama, S., Ishigaki, H., Watanabe, Y. \& Nakamura, T. Mechanism for the peroxideinitiated crosslinking of polyethylene in the presence of 2,4-diphenyl-4-methyl-1pentene. Pol. J. 27, 503-507 (1995).

23 Takamura, M., Nakamura, T., Takahashi, T. \& Koyama, K. Effect of type of peroxide on cross-linking of poly(L-lactide). Polym. Degrad. Stab. 93, 1909-1916 (2008).

24 Cicero, J. A., Dorgan, J. R., Garrett, J., Runt, J. \& Lin, J. S. Effects of molecular architecture on two-step, melt-spun poly(lactic acid) fibers. J. Appl. Polym. Sci. 86, 2839-2846 (2002).

25 Fujio, I. \& Kanaya, T. The Effects of molecular parameter and crystallization condition on flow assisted crystallization. Polym. Prep. Japan 52, 2511-2512 (2003).

26 Brandrup, J. \& Immergut, E. H. in Polymer Handbook Ch. II, 4th edn, 25-26 (John Wiley \& Sons, New York, 1999).

27 Fischer, E. W., Sterzel, H. J. \& Wegner, G. Investigation of the structure of solution grown crystals of lactide copolymers by means of chemical reaction. Kolloid-Zu Z-Polymer 251, 980-990 (1973).

28 Zimm, B. H. \& Stockmayer, W. H. The Dimensions of Chain Molecules Containing Branches and Rings. J. Chem. Phys. 17, 1301 (1949).

29 Davidson, N. S., Fetters, L. J., Funk, W. G., Hadjichristidis, N. \& Graessley, W. W. Measurement of chain dimensions in dilute polymer solutions: a light scattering and viscometric study of linear polyisoprene in cyclohexane. Macromolecules 20, 2614-2619 (1987).

30 Grcev, S., Schoenmakers, P. \& ledema, P. Determination of molecular weight and size distribution and branching characteristics of PVAc by means of size exclusion chromatography/multi-angle laser light scattering (SEC/MALLS). Polymer 45, 39-48 (2004).

31 Sun, T., Brant, P., Chance, R. R. \& Graessley, W. W. Effect of short chain branching on the coil dimensions of polyolefins in dilute solution. Macromolecules $34,6812-6820$ (2001).

32 Wyatt, P. J. Light scattering and the absolute characterization of macromolecules. Anal. Chim. Acta. 272, 1-40 (1993).

33 Guillou, J. C. L. \& Zinn-Justin, J. Critical exponents for the $n$-vector model in three dimensions from field theory. Phys. Rev. Lett. 39, 95-98 (1977).

34 Gupta, A. K. \& Purwar, S. N. Crystallization of PP in PP/SEBS blends and its correlation with tensile properties. J. Appl. Polym. Sci. 29, 1595-1609 (1984).

35 Wang, L. \& Dong, C. M. Synthesis, crystallization kinetics, and spherulitic growth of linear and star-shaped poly(L-lactide)s with different number of arms. J. Polym. Sci: Part A: Polym. Chem. 44, 2226-2236 (2006).

36 Vasanthankumari, R. \& Pennings, A. J. Crystallization kinetics of poly(L-lactic acid). Polymer 24, 175-178 (1983).

37 Tsuji, H. \& Ikada, Y. Properties and morphologies of poly(L-lactide): 1. Annealing condition effects on properties and morphologies of poly(L-actide). Polymer 36, 2709-2716 (1995).

38 Kalb, B. \& Pennings, A. J. General crystallization behaviour of poly(L-lactic acid). Polymer 21, 607-612 (1980).

39 Shroff, R., Prasad, A. \& Lee, C. Effect of molecular structure on rheological and crystallization properties of polyethylenes. J. Polym. Sci: Part B: Polym. Phys. 34, 2317-2333 (1996). 